\title{
Characteristics of prostaglandin $F$ measurements in the ovarian circulation during the oestrous cycle and early pregnancy in the cow*
}

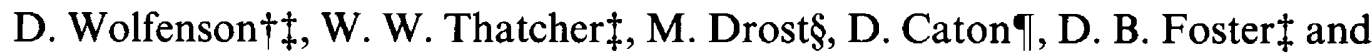 \\ M. M. LeBlanc§
}

$\doteqdot$ Dairy Science Department in Institute of Food and Agricultural Sciences, §Department of Reproduction in College of Veterinary Medicine, and $\mid$ Department of Anaesthesia in College of Medicine, University of Florida, Gainesville, FL 32611, U.S.A.

\begin{abstract}
Summary. Holstein or crossbred beef cows were anaesthetized on Days 15 to 17 after oestrus; the ovarian artery $(\mathrm{OA})$, ovarian (utero-ovarian) vein $(\mathrm{OV})$ and a peripheral artery (PA), were catheterized for chronic blood sampling. Beginning on the day after surgery, 6 sequential blood samples were collected every $30-40$ min twice daily from 8 cyclic and 6 pregnant cows during Days 16-20: 818 blood samples (including 216 OA and PA concurrent arterial pairs) were collected. Overall least squares means for PGF concentrations $(\mathrm{pg} / \mathrm{ml})$ in the OV, OA and PA of cyclic cows were 562, 228 and 106, respectively. A significant $(P<0.01)$ OA-PA difference $(122 \mathrm{pg} / \mathrm{ml})$ suggests that a local transfer system, between uterine venous effluent and ovarian arterial affluent, is functional in the cow. A transfer efficiency of about $1 \%$ was estimated.

In cyclic cows differences in OA-PA concentrations of PGF were minimal on Days 16-18 and increased to about $160 \mathrm{pg} / \mathrm{ml}$ during luteal regression (Days 19-20). In pregnant cows a biphasic OA-PA pattern of difference in PGF between days was detected, with a peak on Day $18(136 \mathrm{pg} / \mathrm{ml})$ which was not apparent on Days 19-20. Amplitude of PGF spikes in the OA was significantly higher in cyclic $(725 \mathrm{pg} / \mathrm{ml})$ than in pregnant cows $(397 \mathrm{pg} / \mathrm{ml})$. We suggest that pregnancy suppresses PGF delivery to the ovarian circulation, resulting in maintenance of the corpus luteum in pregnant cows.
\end{abstract}

\section{Introduction}

The major uterine luteolytic agent in cattle is considered to be prostaglandin (PG) F-2 $\alpha$ (Inskeep \& Murdoch, 1980). The pattern and concentrations of uterine PGF-2 $\alpha$ secretion in the circulation have been characterized. Kindahl, Edqvist, Bane \& Granstrom (1976) and Thatcher et al. (1984) evaluated peripheral plasma concentrations of 15-keto-13,14-dihydro-PGF-2 $\alpha$ (PGFM) in pregnant and cyclic cows. Sequential blood samples were collected in an attempt to characterize the pulsatile pattern of uterine PGF- $2 \alpha$ secretion. The underlying assumption was that the uterus is the major source of PGF-2 $\alpha$ secretion and peripheral PGFM measurements represent it indirectly. Direct evaluation of uterine PGF- $2 \alpha$ secretion in cyclic cows was by a single sample collected at surgery (Shemesh \& Hansel, 1975). Increases of PGF-2 $\alpha$ in uterine venous blood started on Day 14 \footnotetext{
U.S.A.

*Reprint requests to Dr W. W. Thatcher, Dairy Science Department, University of Florida, Gainesville, FL 32611 Israel.

†Present address: Department of Animal Science, Faculty of Agriculture, Hebrew University, Rehovot 76100,
} 
after oestrus, and maximal levels were detected on Days 15-17 and were still high on Day 20 . Involvement of the lymph pathway in the transfer of PGF- $2 \alpha$ from the uterus to the ipsilateral ovary has been suggested (Abdel Rahim, Bland \& Poyser, 1984). Chronic sampling of ovarian arterial blood during late stages of the oestrous cycle or early pregnancy may permit measurement of actual PGF- $2 \alpha$ concentrations that reach the ovary. It may also provide evidence for the existence and functional competence of a local veno-arterial transfer system of PGF- $2 \alpha$ of uterine origin to the ovary. Milvae \& Hansel (1980) measured uterine venous and ovarian arterial concentrations of PGF- $2 \alpha$ in cyclic cows: an increase in uterine venous concentrations of PGF- $2 \alpha$ in response to oxytocin administration was not reflected in ovarian arterial blood. However, the experiment was performed during early stages of corpus luteum (CL) development (Days 4-6); furthermore oxytocin may alter the vasomotor state of the uterine and ovarian vasculature.

The objectives of the present study with cows were: (1) to characterize concentrations and patterns of PGF delivered to the ovarian artery supplying the ovary bearing the CL during early pregnancy or the oestrous cycle (Days 16-20) and (2) to examine the possibility of local transfer of PGF from the uterine venous effluent to the ovarian arterial affluent.

\section{Materials and Methods}

Animals. The 26 Holstein or crossbreed beef cows were non-lactating and multiparous and exhibited regular oestrous cycles. They were managed in facilities of the Dairy Research Unit, Dairy Science Department, and checked twice daily for standing oestrus. Thirteen cows were mated naturally on the day of oestrus (Day 0). Cows were scheduled for surgery on Days 15-17 after oestrus.

Surgical procedure. Food was withheld for $40 \mathrm{~h}$ and water for $24 \mathrm{~h}$ before surgery. General anaesthesia was induced with i.v. injection of thiamylal sodium (Biotal: Bio-Ceutic Laboratories, St Joseph, MO, U.S.A.) and surgical anaesthesia was maintained with fluothane (Vescor, Orlando, FL, U.S.A.). The reproductive tract was exposed through a midline incision and catheters were placed into vessels ipsilateral to the ovary bearing the CL. Ovarian arterial blood was sampled through a catheter placed in the uterine branch of the ovarian artery (UBOA). A polyvinyl catheter $(0.86 \mathrm{~mm}$ i.d., $1.52 \mathrm{~mm}$ o.d.) was introduced into the artery and fixed in place with the tip located 1-2 cm distal to the bifurcation of the UBOA and ovarian artery (OA). The UBOA was ligated downstream of the point where the catheter was introduced to the vessel; arterial blood could not therefore reach the ovary via the uterine artery, utero-ovarian arterial anastomosis, UBOA and $O A$ route. Such a preparation permitted sampling of ovarian arterial blood as close as possible to the ovary, downstream of the area of potential veno-arterial transfer, without interrupting the normal ovarian blood supply. Examination of the utero-ovarian vascular anatomy after slaughter indicated that, in our experimental cows, the area of potential veno-arterial transfer was located upstream of the point at which the UBOA arose from the OA, similar to the vascular arrangement shown by Ginther (1976). A small branch of the uterine branch of the ovarian vein (UBOV) close to the uterine horn was exposed, and a catheter was introduced into the vein with the tip located in the ovarian vein (OV). Earlier attempts to sample uterine venous blood (tip of catheter in UBOV) failed. Therefore, samples from the ovarian vein represent uterine as well as ovarian venous blood. For peripheral blood samples, the facial artery was catheterized and the tip of the catheter advanced into the common carotid artery. After surgery cows were treated i.m. for 5 days with $10 \mathrm{ml}$ ampicillin $(167 \mathrm{mg} / \mathrm{ml}$; Bristol Labs, NY, U.S.A.). No infections developed and body temperatures remained normal.

Experimental procedure. On the day after surgery, 6 sequential 5-ml blood samples were collected from 3 catheters every 30-40 min twice daily $(07: 00-11: 00 \mathrm{~h} ; 17: 00-21: 00 \mathrm{~h})$ from Days 16 to 20 after oestrus. Heparinized syringes were cooled in ice water before use. Blood samples were 
kept on ice and centrifuged within $40 \mathrm{~min}$ at $4^{\circ} \mathrm{C}$. Plasma samples were stored at $-20^{\circ} \mathrm{C}$. At the end of the sampling period or when catheters became non-functional, uterine horns of inseminated cows were flushed twice, non-surgically via the cervix, with $50 \mathrm{ml}$ sterile saline $(9 \mathrm{~g} \mathrm{NaCl} / \mathrm{l})$ to verify the presence of a conceptus (Bartol et al., 1981). At about 3 weeks after surgery, cows were slaughtered, and the exact locations of the UBOA and UBOV catheters were verified.

Hormone assay procedures. Progesterone concentrations were measured utilizing a modification of the procedure described by Eley, Thatcher, Head, Collier \& Wilcox (1981). Major modifications were that: samples were extracted for progesterone, utilizing the method of Louis, Hafs \& Seguin (1973); the antiserum, described by Eley et al. (1981), was utilized in a double-antibody radioimmunoassay system. Mean recovery of radiolabelled progesterone utilizing $2 \mathrm{ml}$ benzene: hexane $(1: 2 \mathrm{v} / \mathrm{v})$, was $86 \cdot 2 \%$. After extraction of unknown plasma samples $(50-200 \mu \mathrm{l})$, solvent was dried under air in a water bath at $37^{\circ} \mathrm{C}$. Standard curves were run in triplicate at the following doses: $31 \cdot 2,62 \cdot 5,125,250,350,500,750,1000$ and $1500 \mathrm{pg} / 0 \cdot 1 \mathrm{ml}$ phosphate-buffered saline and gelatin, $\mathrm{pH} 7.5$ (PBSG): $2 \mathrm{ml}$ benzene:hexane (1:2 v/v) had been added previously and dried in each tube of the standard curve. Each unknown sample received $100 \mu$ PBSG, and all tubes (standards and unknowns) received $400 \mu$ PBSG containing $8 \mu \mathrm{g}$ rabbit gamma globulin, $100 \mu \mathrm{l}$ progesterone antiserum (1:7000 dilution) and 32000 d.p.m. $\left[1,2-{ }^{3} \mathrm{H}\right]$ progesterone (pregn-4-ene-3,20 dione) (s.p. act. $50.3 \mathrm{Ci} / \mathrm{mmol}$; counting efficiency equals $62 \%$ ) in $100 \mu \mathrm{l} \mathrm{PBSG}$. After a $30-\mathrm{min}$ incubation period at $37^{\circ} \mathrm{C}, 50 \mu \mathrm{l}$ of sheep anti-rabbit serum were added and incubated for $12 \mathrm{~h}$ at $4^{\circ} \mathrm{C}$. After addition of PBSG $(2 \mathrm{ml})$ to each tube, they were centrifuged at $2600 \mathrm{~g}$, the supernatant was decanted, $300 \mu \mathrm{l}$ absolute ethanol were added to each tube, and all tubes were vortexed. Radioactivity was quantitated after addition of a toluene cocktail $(3 \mathrm{ml})$. The assay resulted in $26 \%$ binding and an assay sensitivity of $15 \mathrm{pg}$ /tube. In 10 assays exogenous standards of $25,50,250$ and $500 \mathrm{pg}$ were added to $200 \mu$ l ovariectomized cow plasma containing $0.113 \mathrm{ng}$ progesterone $/ \mathrm{ml}$. Mean recovery of exogenous progesterone, corrected for isotopic procedural losses, gave a linear recovery of $\hat{y}=20.73+0.9612 x$ (where $\hat{y}=\operatorname{pg}$ recovered $/ 0.2 \mathrm{ml}$ and $x=\operatorname{pg}$ added $/ 0.2 \mathrm{ml}, R^{2}=0.96$ ). Intraand interassay coefficients of variation were $15.5 \%$ and $17 \cdot 5 \%$, respectively.

Concentrations of PGF- $2 \alpha$ were measured in unextracted plasma samples $(50,100$ and $200 \mu l)$ using a dextran-coated charcoal radioimmunoassay. The antibody (gift from Dr K. Kirton of the Upjohn Company, Kalamazoo, MI) was generated in a goat against PGF- $2 \alpha$ conjugated to bovine serum albumin at the $\mathrm{C}_{1}$ position. Tritiated PGF- $2 \alpha\left(\left[5,6,8,9,11,12,14,15-{ }^{3} \mathrm{H}(\mathrm{N})\right] \mathrm{PGF}-2 \alpha\right.$ : sp. act. 150-180 Ci/mmol), was purchased from New England Nuclear (Boston, MA, U.S.A.). Crossreactivities were: $53.6 \%$ for PGF-1 $\alpha ; 0.8 \%$ for 6 -keto-PGF-1 $\alpha ; 0.22 \%$ for 15 -keto-PGF-2 $\alpha$; and $<0.04 \%$ for 15-keto-13,14-dihydro-PGF-2 $\alpha$, PGE-1, PGE-2 and arachidonic acid. Standard curves were prepared by adding known amounts of radioinert PGF-2 $\alpha(10,25,50,100,250,500$, 1000 and $2500 \mathrm{pg})$ to bovine plasma $(0 \cdot 2 \mathrm{ml})$ obtained from cattle treated with flunixin meglumine (Banamine: Schering Corp., Kenilworth, NJ) to suppress prostaglandin synthesis (Guilbault, Thatcher, Drost \& Hopkins, 1984). Sensitivity of the assay was $10 \mathrm{pg} / \mathrm{tube}$. Exogenous standards of $25,50,100,125,200,250$ and $500 \mathrm{pg}$ were added to $200 \mu \mathrm{l}$ of prostaglandin-free plasma. Mean recovery of exogenous PGF- $2 \alpha$ gave a linear recovery of $\hat{y}=8.7+1.01 x$ (where $\hat{y}=\mathrm{pg}$ recovered $/ 0.2 \mathrm{ml}$ and $x=\mathrm{pg}$ added $/ 0.2 \mathrm{ml}, R^{2}=0.97$ ). Interassay and intraassay coefficients of variation for 12 assays were $8 \cdot 1 \%$ and $12 \cdot 9 \%$, respectively. As PGF-2 $\alpha$ antiserum cross-reacted with PGF-1 $\alpha$, data will be expressed in this study as PGF.

Statistical analysis. Results were analysed by least square analysis of variance according to methods available in the General Linear Models Procedures of the Statistical Analysis Systems (SAS; Barr, Goodnight, Sall, Blair \& Chilko, 1979). A split-plot analysis, suitable for repeated measures of each animal, was employed. Frequency distribution of PGF spikes was assessed by $\chi^{2}$ tests. 


\section{Results}

Blood samples could not be obtained from 12 of 26 experimental cows due to surgical difficulties. Average length of the sampling period was 2 days (range 1-4 days). A total of 818 blood samples (average of 58 samples per cow) was collected from 8 cyclic and 6 pregnant cows and included 216 concurrent pairs of ovarian and peripheral arterial blood samples. Ovarian vein concentrations of PGF are from cyclic cows only; for pregnant cows an insufficient number of such samples was obtained to permit proper statistical analysis. The mathematical model for the least squares analysis of variance of PGF concentrations in the ovarian and peripheral arteries during the oestrous cycle and pregnancy is presented in Table 1. Plasma concentrations of PGF differed amongst cows within status (cyclic $>$ pregnant; $P<0.01$ ) and concentrations of PGF differed in plasma between vessels $(\mathrm{OA}>\mathrm{PA} ; P<0.01)$. The interaction of status by days after oestrus by vessel was significant $(P<0.01)$ and of potential physiological significance.

Table 1. Least squares analysis of variance for PGF during the oestrous cycle and early pregnancy in cows

\begin{tabular}{lrcc}
\hline Source & d.f. & MS & Error term \\
\hline Status $\dagger$ & 1 & 9239 & $\mathrm{C}(\mathrm{S})$ \\
Cow (status) & 9 & $278110^{* *}$ & $\mathrm{R}$ \\
Day & 3 & 10753 & $\mathrm{R}$ \\
Vessel $\neq$ & 1 & $470263^{* *}$ & $\mathrm{R}$ \\
Status $\times$ Vessel & 1 & $41044^{\mathrm{a}}$ & $\mathrm{R}$ \\
Status $\times$ Day $\times$ Vessel & 9 & $84902^{* *}$ & $\mathrm{R}$ \\
Residual $(\mathrm{R})$ & 391 & 15144 & $\mathrm{R}$ \\
\hline
\end{tabular}

${ }^{* *} P<0.01,{ }^{2} P<0 \cdot 10$.

$\dagger$ Status (pregnant $v s$ cyclic).

$\ddagger$ Vessel (ovarian vs peripheral arteries).

\section{Patterns of PGF in cyclic cows}

The PGF values in ovarian vein and artery and peripheral artery of cyclic cows between Days 16 and 20 are given in Table 2. A clear increase in PGF was detected in the ovarian vein on Days 18, 19 and 20 . A sub-sample of 82 sample times was evaluated when blood was collected concurrently from all three sites (Table 3$)$. A day effect $(P<0.05)$ on ovarian vein concentrations of PGF was noted with minimal and maximal amounts on Day 17 and on Day 20, respectively. The ovarian artery concentrations of PGF on Days 17-18 were within the basal range of PGF in the peripheral circulation. Concurrent with the ovarian vein rise in PGF on Days 19-20, PGF concentrations in the ovarian artery increased by more than 2-fold above those on Days 17-18, and the ovarian and peripheral artery difference also increased $(P<0.05$ for day effect). The latter change indicates that concentrations of PGF in the ovarian arterial blood may have been transferred locally from the ovarian vein. Concentrations of PGF in the ovarian vein were associated with those in the ovarian artery of cyclic cows $(r=0.46, P<0.01)$. A mean PGF concentration difference (OA-PA) of $85 \mathrm{pg} / \mathrm{ml}$ represents $10 \%$ of the mean ovarian vein concentration $(810 \mathrm{pg} / \mathrm{ml})$. Mean progesterone concentrations for all cyclic cows between Days 16 and 21 were $6 \cdot 8,7 \cdot 4,6 \cdot 0,4 \cdot 8,3 \cdot 6$ and $1 \cdot 8 \mathrm{ng} / \mathrm{ml}$ ). The transitory decrease in peripheral progesterone concentrations associated with luteolysis was associated with temporal increases of PGF concentrations in the ovarian vein and with net increases in concentrations of PGF (OA-PA) in the ovarian artery (Tables $2 \& 3$ ). 
Table 2. Mean \pm s.e.m. PGF concentrations in the ovarian vein (OV), ovarian artery $(\mathrm{OA})$ and peripheral artery (PA) of cows $(\mathrm{N}=8)$ during the oestrous cycle

\begin{tabular}{|c|c|c|c|}
\hline \multirow[b]{2}{*}{ Day } & \multicolumn{3}{|c|}{ PGF conc. (pg/ml) } \\
\hline & ov & $\mathrm{OA}$ & PA \\
\hline $\begin{array}{l}16 \\
17 \\
18 \\
19 \\
20\end{array}$ & $\begin{aligned} 256 & \pm 59 \\
230 & \pm 36 \\
1154 & \pm 412 \\
544 & \pm 188 \\
728 & \pm 240\end{aligned}$ & $\begin{array}{l}162 \pm 32 \\
109 \pm 22 \\
156 \pm 31 \\
302 \pm 40 \\
248 \pm 47\end{array}$ & $\begin{array}{r}174 \pm 37 \\
76 \pm 12 \\
122 \pm 24 \\
101 \pm 10 \\
75 \pm 9\end{array}$ \\
\hline Mean \pm s.e.m. $(n)$ & $562 \pm 115$ & $228^{*} \pm 15 \quad$ & $106^{*} \pm 14$ \\
\hline
\end{tabular}

${ }^{*} P<0.01$.

Table 3. PGF (pg/ml) concentrations in concurrent samples of ovarian vein $\left(\mathrm{O}^{\mathbf{r}}\right)$, ovarian artery $(\mathrm{OA})$ and peripheral artery $(\mathrm{PA})$ of cows $(\mathrm{N}=8)$ during the oestrous cycle

\begin{tabular}{lcccccc}
\hline & & & & & \multicolumn{2}{c}{ OA-PA } \\
\cline { 5 - 7 } Day & OV* & OA & PA & OA-PA** & OV & $n \dagger$ \\
\hline 17 & 215 & 126 & 94 & 32 & $14 \cdot 9$ & 25 \\
18 & 325 & 54 & 50 & 4 & $1 \cdot 2$ & 18 \\
19 & 1095 & 272 & 104 & 168 & $15 \cdot 3$ & 24 \\
20 & 1595 & 243 & 108 & 135 & $8 \cdot 5$ & 15 \\
Mean & $810 \pm 170$ & $174 \pm 20$ & $84 \pm 8$ & $85 \pm 16$ & $10 \cdot 0 \pm 3 \cdot 3$ & 82 \\
\pm s.e.m. & & & & & & \\
\hline
\end{tabular}

$* P<0.05$,

$* * P<0.01$.

$\dagger n=$ number of concurrent triplicate samples $(\mathrm{OV}, \mathrm{OA}, \mathrm{PA})$.

\section{Responses of cyclic and pregnant animals}

Cows were considered pregnant $(\mathrm{N}=6)$ if a conceptus was recovered at the non-surgical flush following the sampling period for each cow that was mated $(N=13)$. Overall mean concentrations of PGF in the ovarian and peripheral arteries of pregnant cows were $175 \pm 16$ and $105 \pm 10.0 \mathrm{pg} / \mathrm{ml}$, respectively. Differences between pregnant and cyclic cows, in the PGF ovarian to peripheral arterial gradient (OA-PA) during Days 17-20 after oestrus, are presented in Table 4. A status-by-day interaction $(P<0.01)$ was detected. The relatively high concentrations of PGF detected on Days 19 and 20 in cyclic animals were not detected in pregnant animals during those days. Representative data from one pregnant and one cyclic cow are shown in Text-fig. 1. The OA-PA difference for PGF gradually increased from Days 17 to 20 in the cyclic cow, whereas in the pregnant cow a biphasic pattern was noted, with a moderate rise on Day 18 followed by a decline toward Day 20. In general, data in Text-fig. 1 reflect a trend similar to that for the mean of all cows presented in Table 4.

Because PGF secretion is episodic, the pattern of PGF concentrations in the ovarian artery of pregnant and cyclic cows was also evaluated by spike analysis. A spike of PGF in the ovarian artery was defined as a value of PGF above the mean +2 standard deviations for each animal. The distributions of spikes among the pregnant ( 9 spikes within 98 samples) and cyclic (12 spikes within 
Table 4. Least squares means \pm s.e.m. for difference in PGF concentrations between ovarian and peripheral arteries $(\mathrm{OA}-\mathrm{PA})$ of pregnant $(\mathrm{N}=5)$ and cyclic $(\mathrm{N}=6)$ cows

\begin{tabular}{|c|c|c|}
\hline \multirow[b]{2}{*}{ Day } & \multicolumn{2}{|c|}{ PGF conc. $(\mathrm{pg} / \mathrm{ml})$} \\
\hline & Pregnant* & Cyclic* \\
\hline $\begin{array}{l}17 \\
18 \\
19 \\
20\end{array}$ & $\begin{array}{r}29 \pm 25(39) \\
136 \pm 37(17) \\
70 \pm 38(17) \\
54 \pm 46(11)\end{array}$ & $\begin{array}{r}38 \pm 26(30) \\
1 \pm 28(35) \\
167 \pm 31(28) \\
161 \pm 35(21)\end{array}$ \\
\hline Mean (sample number) & $72 \pm 21(84)$ & $92 \pm 19(114)$ \\
\hline
\end{tabular}

* $P<0.01$ Status $\times$ Day interaction.

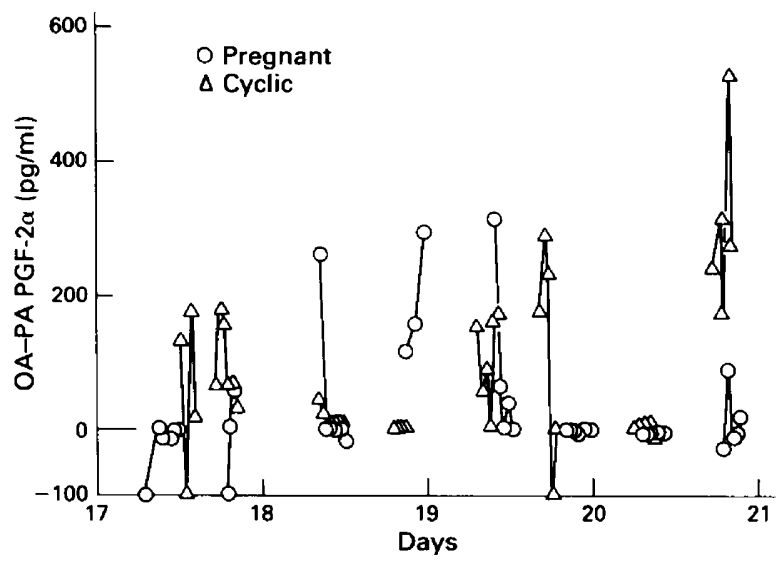

Text-fig. 1. Ovarian-peripheral arterial differences of one cyclic cow and one pregnant cow during Days 17-20 after oestrus.

Table 5. Least squares means \pm s.e.m. for positive difference in PGF concentration between ovarian and peripheral arteries (OA-PA) of pregnant and cyclic animals

\begin{tabular}{lcc}
\hline Response & Pregnant & Cyclic \\
\hline No. of cows & 5 & 7 \\
No. of OA-PA pairs & 90 & 138 \\
No. of positive OA-PA pairs (\%) & $46(51 \cdot 1)$ & $73(52 \cdot 8)$ \\
PGF conc. (pg/ml) of positive & $117 \pm 11 \cdot 1$ & $200 \pm 14 \cdot 8$ \\
OA-PA pairs & \\
\hline
\end{tabular}

136 samples) cows for PGF were not different statistically. However, mean amplitude of a spike in a pregnant cow was about one-half that detected for a cyclic cow $(397 \pm 196$ and $725 \pm 189 \mathrm{pg} / \mathrm{ml}$, respectively; $P<0.01$ ).

Estimates in Table 4 include the entire data set and encompass sample times when the OA-PA difference (as demonstrated in Text-fig. 1) was negative $(16 \%)$, zero $(32 \%)$ or positive $(52 \%)$. A zero (or negative) OA-PA difference means that, during that sample time, a concentration gradient between uterine effluent secretion and the ovarian artery did not exist to drive a local exchange system. Furthermore, PGF is secreted in an intermittent manner. Therefore, it is assumed that 
positive OA-PA differences were associated with periods when uterine PGF was secreted and transferred to the ovarian arterial circulation. Table 5 contains the PGF means for OA-PA differences that are positive in cyclic (range $1-636 \mathrm{pg} / \mathrm{ml}$ ) and pregnant (range $1-384 \mathrm{pg} / \mathrm{ml}$ ) cows. The mean OA-PA difference of $83 \mathrm{pg} / \mathrm{ml}$ between cyclic and pregnant cows is most probably a more accurate estimate of the physiological mean difference compared to a more conservative estimate of $20 \mathrm{pg} / \mathrm{ml}$ shown in Table 4 . Mean progesterone concentrations for all pregnant cows between Days 16 and 20 were $10 \cdot 2,8 \cdot 6,10 \cdot 5,8 \cdot 5$ and $6 \cdot 7 \mathrm{ng} / \mathrm{ml}$.

\section{Discussion}

The potential presence of a local mechanism controlling ovarian function by the uterine horn ipsilateral to the CL has been studied in cattle by surgical manipulations (Malven \& Hansel, 1964; Hixon \& Hansel, 1974; Lamond \& Drost, 1974). Hixon \& Hansel (1974) also examined the local venoarterial transfer system by injecting radio-labelled PGF-2 $\alpha$ into the lumen of the uterine horn. While the peripheral concentration of PGF-2 $\alpha$ was highest within $5 \mathrm{~min}$, the concentration of PGF-2 $\alpha$ in the ovarian artery increased to reach a peak at 40 min after treatment. Results of this study in cows were similar to comparable experiments with sheep (McCracken, Carlson, Glew, Goding \& Baird, 1972; Land, Baird \& Scaramuzzi, 1976). These studies suggested that the local countercurrent veno-arterial transfer system of PGF- $2 \alpha$ is functional in sheep and cattle. However, when endogenous concentrations of PGF- $2 \alpha$ were measured in single samples collected from cyclic cows at surgery (Shemesh \& Hansel, 1975; Lukaszewska \& Hansel, 1980), higher PGF-2 $\alpha$ concentrations were not detected in the ovarian artery as compared to peripheral concentrations. In the present experiment, with several samples taken chronically on a within-cow basis, concentrations of PGF in the ovarian artery were higher than those of the peripheral artery. An additional mean concentration of $122 \mathrm{pg} \mathrm{PGF} / \mathrm{ml}$, above a mean basal peripheral concentration $(106 \mathrm{pg} / \mathrm{ml})$, was detected in the ovarian artery of cyclic cows (Table 2). Analysis of PGF concentrations at peak secretion (e.g. spike analysis) indicated that mean PGF concentrations in the ovarian and peripheral arteries (pooled across cyclic and pregnant cows) were 599 and $270 \mathrm{pg} / \mathrm{ml}$, respectively $(P<0.01)$. These findings suggest that concentrations of PGF above peripheral basal concentrations $(106 \mathrm{pg} / \mathrm{ml})$ could be detected in peripheral blood $(270 \mathrm{pg} / \mathrm{ml})$ when massive secretion of PGF was released into the circulation. This probably reflected the limit of PGF-2 $\alpha$ degradation by the lungs (Davis, Fleet, Hansford, Harrison \& Walker, 1981).

A significant correlation $(r=0.46, P<0.01)$ was detected between concentrations of PGF in the ovarian veins and arteries of cyclic cows ( $O V>O A)$. This in-vivo relationship is in agreement with the results of a study on uptake of PGF- $2 \alpha$ by tissues of the ovarian artery and vein incubated in vitro (Curl \& Thatcher, 1983; Thatcher et al., 1984). Uptake of PGF-2 $\alpha$ by the ovarian vein was significantly higher than that measured for the ovarian artery. Both studies suggest a simple diffusion of PGF-2 $\alpha$ across the walls of the two vessels. In this respect, lymph has been suggested as an additional pathway of PGF-2 $\alpha$ from the uterus to the ipsilateral ovary (Abdel Rahim et al., 1984).

Results in Table 3 indicated that, on the average, $10 \%$ of PGF in the ovarian vein was transferred to the ovarian artery. This calculation does not consider transfer efficiency quantitatively. To obtain such data, estimates of uterine blood flow and ovarian blood flow are required. Based on data of Ford \& Chenault (1981), when uterine and ovarian blood flow were measured simultaneously in cyclic cows, a uterine:ovarian ratio of 10:1 was obtained in the late luteal phase. Therefore, a transfer factor of about $1 \%$ may be estimated for the veno-arterial system. Such an estimate is in a good agreement with data from acute studies in sheep (McCracken et al., 1972; Land et al., 1976) in which the transfer factor ranged between 0.2 and $2 \%$. It also is compatible with efficiency of the counter-current exchange system of steroid hormones found in the sheep ovarian pedicle (range $1 \cdot 2-2 \cdot 7 \%$ for various steroids; Einer-Jensen \& McCracken, 1981 ). 
An essential response is the association of luteal regression with the increase in uterine secretion of PGF-2 $\alpha$. These are in close coincidence in cows, sheep and other species around the time of onset of luteal regression (Inskeep \& Murdoch, 1980). Higher concentrations and larger peaks of PGF-2 $\alpha$ were measured in the uterine vein in sheep, or estimated by peripheral PGFM values in heifers as CL regression proceeded (Barcikowski, Carlson, Wilson \& McCracken, 1974; Kindahl et al., 1976). It has been suggested that in the cyclic animal luteal regression starts in response to relatively moderate peaks of PGF- $2 \alpha$ secretion, and its continuation is dependent on the larger peaks that appear later (McCracken, Schramm, Barcikowski \& Wilson, 1981). In the present experiment, a similar trend was also evident at the ovarian level (Table 3). In cyclic cows, higher values of ovarian and peripheral arterial differences in PGF were detected during advanced stages of CL regression $(135 \mathrm{pg} / \mathrm{ml}$, Day 20$)$ compared to earlier stages $(32 \mathrm{pg} / \mathrm{ml}$, Day 17). A similar trend is also demonstrated in Text-fig. 1 .

A major objective of this study was to evaluate whether pregnancy status altered the pattern and concentration of PGF transferred to the ovary. Greater concentrations of PGF were detected in ovarian artery (OA-PA) of cyclic cows during the period of normal luteal regression (Days 19 and 20), whereas an increase was not detected during this period in pregnant cows (Table 4). The pattern of PGF in the ovarian artery of pregnant cows is characterized by a biphasic response with peak PGF concentration on Day 18. Exact reasons for the difference between responses of pregnant and cyclic cows are not yet known. Reduced in-vitro uptake of PGF- $2 \alpha$ by endometrial and ovarian vasculature tissues of pregnant compared to cyclic animals and a difference in primary sources of PGF- $2 \alpha$ between pregnant (conceptus plus endometrium) and cyclic (endometrium only) cows may account for the physiological differences (Curl \& Thatcher, 1983; Thatcher et al., 1984).

Thatcher et al. (1984) and Rico, Thatcher, Drost, Wolfenson \& Terqui (1981) reported that the increase of uterine PGF-2 $\alpha$ production in vivo, induced by i.v. injection of oestradiol-17 $\beta$ and assessed by peripheral PGFM concentrations, was significantly lower in Day 18 and Day 20 pregnant cows compared to Day 18 cyclic cows. The presence of the conceptus therefore resulted in reduced endometrial PGF- $2 \alpha$ secretion and release into the circulation during the period when luteal regression occurs in cyclic animals. Lower concentrations of PGF were found at the ovarian level in pregnant cows compared to cyclic cows of the present study.

Florida Agricultural Experiment Station Journal Series No. 6165. This research was partially supported by a grant from the Lady Davis Fellowship Trust and the Upjohn Co., Kalamazoo, MI. We thank J. J. Knickerbocker for assistance with PGF-2 $\alpha$ analyses.

\section{References}

Abdel Rahim, S.E.A., Bland, K.P. \& Poyser, N.L. (1984) Surgical separation of the uterus and ovaries with simultaneous cannulation of the uterine vein extends luteal function in sheep. J. Reprod. Fert. 72, 231-235.

Barcikowski, B., Carlson, J.C., Wilson, L. \& McCracken, J.A. (1974) The effect of endogenous and exogenous estradiol-17ק on the release of prostaglandin $F_{20}$ from the ovine uterus. Endocrinology 95, 1340-1349.

Barr, A.J., Goodnight, J.H., Sall, J.P., Blair, W.H. \& Chilko, D.M. (1979) SAS User's Guide. SAS Institute Inc., Raleigh, NC.

Bartol, F.F., Thatcher, W.W., Lewis, G.S., Bliss, E.L., Drost, M. \& Bazer, F.W. (1981) Effect of estradiol-17 $\beta$ on PGF and total protein content in bovine uterine flushings and peripheral plasma concentration of 13,14-dihydro-15-keto-PGF ${ }_{2 a}$. Theriogenology 15, 345-358.
Curl, J.S. \& Thatcher, W.W. (1983) In vitro uptake of $\mathrm{PGF}_{2 \alpha}$ by tissues from the endometrium, ovarian vein and ovarian artery of cyclic and pregnant cattle at day 17. Biol. Reprod. 28 (Suppl. 1), 108, Abstr.

Davis, A.J., Fleet, I.R., Hansford, P.A., Harrison, F.A. \& Walker, F.M.M. (1981) Pulmonary metabolism of prostaglandin $F_{2 \alpha}$ in the conscious non-pregnant cow. J. Physiol., Lond. 301, 42P, Abstr.

Einer-Jensen, N. \& McCracken, J.A. (1981) Physiological aspects of corpus luteum blood flow and of the counter system in the ovarian pedicle of the sheep. Acta vet. scand., Suppl. 77, 89-101.

Eley, D.S., Thatcher, W.W., Head, H.H., Collier, R.J. \& Wilcox, C.J. (1981) Periparturient endocrine changes of conceptus and maternal units in Jersey cows bred for milk yield. J. Dairy Sci. 64, 296-311.

Ford, S.P. \& Chenault, J.R. (1981) Blood flow to the 
corpus luteum-bearing ovary and ipsilateral uterine horn of cows during the oestrous cycle and early pregnancy. J. Reprod. Fert. 62, 555-562.

Ginther, O.J. (1976) Comparative anatomy of uteroovarian vasculature. Scope 20, 1-17.

Guilbault, L.A., Thatcher, W.W., Drost, M. \& Hopkins, S.M. (1984) Source of F series prostaglandins during the early postpartum period in cattle. Biol. Reprod. 31, 879-887.

Hixon, J.E. \& Hansel, W. (1974) Evidence for preferential transfer of prostaglandin $F_{2 a}$ to the ovarian artery following intrauterine administration in cattle. Biol. Reprod. 11, 543-552.

Inskeep, E.K. \& Murdoch, W.J. (1980) Relation of ovarian functions to uterine and ovarian secretion of prostaglandins during the oestrous cycle and early pregnancy in the ewe and cow. Int. Rev. Physiol. 22, pp. 325-356.

Kindahl, H., Edqvist, L.E., Bane, A. \& Granstrom, E. (1976) Blood levels of progesterone and 15-keto13,14-dihydro-prostaglandin $F_{2 a}$ during the normal oestrous cycle and early pregnancy in heifers. Acta endocr., Copenh, 82, 134-149.

Lamond, D.R. \& Drost, M. (1974) Blood supply to the bovine ovary. J. Anim. Sci. 38, 106-112.

Land, R.B., Baird, D.T. \& Scaramuzzi, R.J. (1976) Dynamic studies of prostaglandin F-2 $\alpha$ in the utero-ovarian circulation of the sheep. J. Reprod. Fert. 47, 209-214.

Louis, T.M., Hafs, H.D. \& Sequin, B.E. (1973) Progesterone, $\mathrm{LH}$, estrus and ovulation after prostaglandin 20 in heifers. Proc. Soc. exp. Biol. Med. 143, 152-155.

Lukaszewska, J. \& Hansel, W. (1980) Corpus luteum maintenance during early pregnancy in the cow. $J$. Reprod. Fert. 59, 485-493.
Malven, P.W. \& Hansel, W. (1964) Ovarian function in dairy heifers following hysterectomy. J. Dairy Sci. 47, 1388-1393.

McCracken, J.A., Carlson, J.C., Glew, M.E., Goding, J.R. \& Baird, D.T. (1972) Prostaglandin $F_{2 \alpha}$ identified as a luteolytic hormone in sheep. Nature, New Biol. 238, 129-134.

McCracken, J.A., Schramm, W., Barcikowski, B. \& Wilson, L. (1981) The identification of prostaglandin $F_{2 a}$ as an uterine luteolytic hormone and the hormonal control of its synthesis. Acta vet. Scand., Suppl. 77, 71-88.

Milvae, R.A. \& Hansel, W. (1980) Concurrent uterine venous and ovarian arterial prostaglandin $F$ concentrations in heifers treated with oxytocin. $J$. Reprod. Fert. 60, 7-15.

Rico, L.E., Thatcher, W.W., Drost, W. Wolfenson, D. \& Terqui, M. (1981) Plasma PGFM responses to estradiol injection in pregnant and cyclic cows. $J$. Anim. Sci. 53 (Suppl. 1), 363, Abstr.

Shemesh, M. \& Hansel, W. (1975) Levels of prostaglandin $\mathrm{F}$ (PGF) in the bovine endometrium, uterine venous, ovarian artery and jugular plasma during the oestrous cycle. Proc. Soc. exp. Biol. Med. 148, 123-126.

Thatcher, W.W., Wolfenson, D., Curl, J.S., Rico, L.E., Knickerbocker, J.J., Bazer, F.W. \& Drost, M. (1984) Prostaglandin dynamics associated with development of the bovine conceptus. Anim. Reprod. Sci. 7, $149-176$. 